Article

\title{
Fabrication and Characterization of Composite Biofilm of Konjac Glucomannan/Sodium Lignosulfonate/ع-Polylysine with Reinforced Mechanical Strength and Antibacterial Ability
}

\author{
Xiaowei Xu and Jie Pang * \\ School of Food Science, Fujian Agriculture and Forestry University, Fuzhou 350002, China; \\ xxiaowei1995@163.com \\ * Correspondence: pang3721941@fafu.edu.cn; Tel.: +86-186-5073-1906
}

check for updates

Citation: Xu, X.; Pang, J. Fabrication and Characterization of Composite Biofilm of Konjac

Glucomannan/Sodium

Lignosulfonate / $\varepsilon$-Polylysine with Reinforced Mechanical Strength and Antibacterial Ability. Polymers 2021, 13, 3367. https://doi.org/10.3390/ polym13193367

Academic Editors: Sergio Torres-Giner and Maria Vargas

Received: 23 August 2021

Accepted: 27 September 2021

Published: 30 September 2021

Publisher's Note: MDPI stays neutral with regard to jurisdictional claims in published maps and institutional affiliations.

Copyright: (C) 2021 by the authors Licensee MDPI, Basel, Switzerland. This article is an open access article distributed under the terms and conditions of the Creative Commons Attribution (CC BY) license (https:// creativecommons.org/licenses/by/ $4.0 /)$

Abstract: In order to enforce the mechanical strength and antibacterial ability of biofilm and explore the underlying mechanism, sodium lignosulfonate (SL) and $\varepsilon$-polylysine ( $\varepsilon$-PL) were introduced to fabricate the composite film of konjac glucomannan (KGM)/SL/ $\varepsilon-\mathrm{PL}$ in the present study. According to our previous method, $1 \%(w / v)$ of KGM was the optimal concentration for the film preparation method, on the basis of which the amount of SL and $\varepsilon$-PL were screened by mechanical properties enforcement of film. The structure, mechanical performance and thermal stability of the film were characterized by SEM, FTIR, TGA and tensile strength tests. The optimized composite film was comprised of KGM 1\% $(w / v)$, SL $0.2 \%(w / v)$, and $\varepsilon$-PL $0.375 \%(w / v)$. The tensile strength $(105.97 \pm 4.58 \mathrm{MPa}$, $p<0.05)$ and elongation at break $(95.71 \pm 5.02 \%, p<0.05)$ of the KGM/SL/ $\varepsilon$-PL composite film was greatly improved compared with that of KGM. Meanwhile, the thermal stability and antibacterial property of film were also enhanced by the presence of SL and $\varepsilon$-PL. In co-culturation mode, the $\mathrm{KGM} / \mathrm{SL} / \varepsilon$-PL composite film showed good inhibitory effect on Escherichia coli $(22.50 \pm 0.31 \mathrm{~mm}$, $p<0.05)$ and Staphylococcus aureus $(19.69 \pm 0.36 \mathrm{~mm}, p<0.05)$ by determining the inhibition zone diameter. It was revealed that KGM/SL/ $\varepsilon$-PL composite film shows enhanced mechanical strength and reliable antibacterial activities and it could be a potential candidate in the field of food packaging.

Keywords: konjac glucomannan (KGM); KGM/SL/E-P; composite film; food packaging

\section{Introduction}

Konjac glucomannan (KGM) is a natural polymer found in konjac tubers showing unique physical and chemical properties because of its large molecular weight and complex chemical structure [1]. Compared with some other natural polymer materials, KGM has a larger molecular weight and a higher content of hydroxyl and acetyl groups. Therefore, KGM has stronger viscosity and hydrophilicity, and its hydrosol can form a dense and smooth film after drying [2]. KGM is widely used in some fields including the food packaging or medicine industry due to its good biocompatibility, biodegradability and good film-forming ability [3,4]. However, pure KGM films show several disadvantages such as poor mechanical properties and insufficient stability. In order to solve this problem, researchers have adopted a variety of methods to improve the mechanical strength, stability and other properties [5,6]. For example, it can be combined with other polysaccharides and proteins, metal nanoparticles, and reinforcing fibers (such as glass fibers, cellulose nanocrystals, and cellulose nanofibers) to improve performance [7-10]. However, with the large-scale use of metal nanoparticles and chemical synthetic fibers, this has also caused people to worry about the environmental pollution of metal nanoparticles. Some natural biological polymers such as lignin and its derivate could be environmentally friendly used for their easy aggregation to avoid pollution problems.

In this work, SL and $\varepsilon$-PL were introduced to improve mechanical strength, antibacterial ability and thermal properties of the KGM film as showed by performing tensile tests, 
TGA and antibacterial assessment. The structure of the developed films was evaluated by FTIR and SEM analysis. Lignin, as a rich biomass resource of plants, mainly exists in the cell walls of plants which improve the hardness and strength of plant tissues by virtue of the three-dimensional network structure [11,12]. Lignin is the third most amount of carbohydrate only next to cellulose and chitin. However, lignin, a very complex structure existing in a large number of plants, is generally discarded as waste. Over the recent decades, the highvalue utilization of lignin has received extensive attention from researchers [13-16], who mainly focused on the application of lignin and its derivatives. The rational development and utilization of lignin has important research significance and conforms to the concept of sustainable development $[17,18]$. Lignosulfonate is a derivative of lignin extracted from liquid waste during pulping and papermaking processes [19-21]. Lignosulfonate is utilized as dispersants, water reducers and other low value-added products. In recent years, lignosulfonate was used as an anti-ultraviolet additive, a strengthening agent for films and gel materials in high-quality applications [22-25]. These unique properties of lignosulfonate are utilized to overcome the shortcomings of poor mechanical strength of konjac glucomannan, which is beneficial to the development of low-cost, high-performance composite materials.

$\varepsilon$-PL is a high molecular peptide with antibacterial effect on common bacteria, such as Staphylococcus aureus and Escherichia coli. $\varepsilon$-PL destroyed the cell membrane structure of microorganisms by interruption of cell material, energy and information transmission, and ultimately leading to cell death $[26,27]$. Therefore, $\varepsilon$-PL is a good food preservative and antibacterial agent [28,29].

In this work, SL and $\varepsilon$-PL were introduced to improve the mechanical strength, antibacterial ability and thermal properties of the KGM film. The structure and performance of the film were characterized by SEM, FTIR, TGA and mechanical performance tests. The underlying mechanism of gel formation among KGM, SL and $\varepsilon$-PL was explored, Figure 1 shows the hydrogen bonding between polymer chains in detail. The antibacterial activities against the growth of Escherichia coli and Staphylococcus aureus were evaluated by the Oxford Cup test. The excellent performance of KGM/SL/ $\varepsilon-\mathrm{PL}$ composite film was proved, and it could be a potential candidate for food packaging.

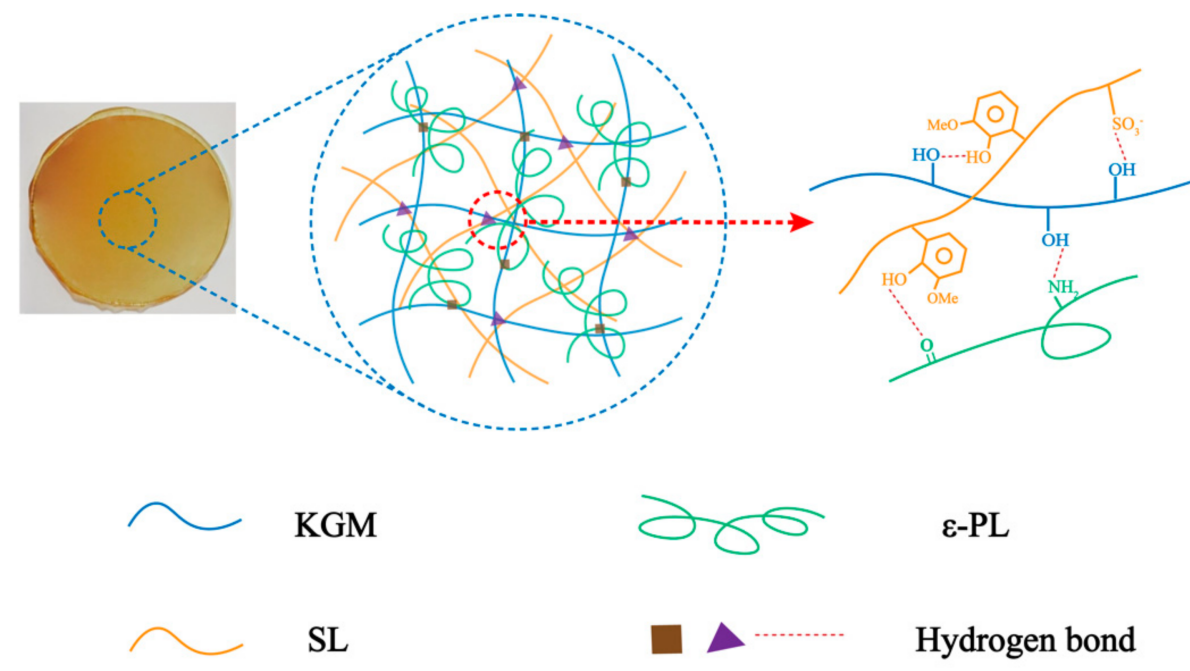

Figure 1. Mechanism diagram.

\section{Materials and Methods}

\subsection{Materials}

Konjac glucomannan (KGM, 95\%) was purchased from Yunnan Zhaotong San'ai Organic Konjac Development Co., Ltd. (Zhaotong, China). Both sodium lignosulfonate (SL) and $\varepsilon$-polylysine ( $\varepsilon$-PL) were obtained from Shanghai Aladdin Biochemical Technology Co., Ltd (Shanghai, China). Glycerin and $\mathrm{Na}_{2} \mathrm{CO}_{3}$ (AR) were purchased from Sinopharm 
Chemical Reagent Co., Ltd (Shanghai, China). Deionized water was used in all experiments. Escherichia coli (ATCC 11775) and Staphylococcus aureus (ATCC 27735) were obtained from the School of Food Science, Fujian Agriculture and Forestry University (Fuzhou, China).

\subsection{Preparation of KGM Films}

According to the procedures of preparing KGM solution in our research group, KGM powder $(1.00 \mathrm{~g})$ was dissolved into $100 \mathrm{~mL}$ deionized water while mechanically stirred for $1 \mathrm{~h}$ to and thoroughly swelled to obtain a KGM control solution $[30,31]$. The solution was centrifuged at $3000 \mathrm{rpm}$ for $6 \mathrm{~min}$ to be degassed. The centrifuged solution $(30 \mathrm{~mL})$ was poured into a petri dish $(\Phi 90 \mathrm{~mm})$. After being wrapped in plastic with holes to allow water to evaporate, the solution was dried in a $50{ }^{\circ} \mathrm{C}$ oven to obtain intact KGM film.

\subsection{Preparation of KGM/SL Films}

After the addition of $0.10 \mathrm{~g}$ SL powder into $100 \mathrm{~mL}$ deionized water, the solution was mechanically stirred for $10 \mathrm{~min}$ to obtain $0.1 \%$ SL solution. Then $1.00 \mathrm{~g}$ KGM powder was added into above $0.1 \%$ SL solution and was thoroughly swelled with another $1 \mathrm{~h}$ agitation to obtain $0.1 \%$ mixed KGM/SL solution. When the serial amounts of SL powder $0.20,0.30,0.40$, and $0.50 \mathrm{~g}$ were added to obtain $0.2,0.3,0.4$, and $0.5 \%$ mixed KGM/SL solutions respectively. The solutions were centrifuged at $3000 \mathrm{rpm}$ for $6 \mathrm{~min}$ to degas [32]. Each centrifuged solution $(30 \mathrm{~mL})$ was poured into a petri dish $(\Phi 90 \mathrm{~mm})$ which was wrapped by plastic with holes to allow water to evaporate. The mixed solution was dried in oven $\left(50^{\circ} \mathrm{C}\right)$ to obtain intact $(0.1,0.2,0.3,0.4$, and $0.5 \%) \mathrm{KGM} / \mathrm{SL}$ composite films. The mechanical strength of all the prepared films were evaluated as the method in 2.5. The composite film of $0.2 \% \mathrm{KGM} / \mathrm{SL}$ exhibited the strongest mechanical strength, so $0.2 \% \mathrm{SL}$ was chosen as the optimal amount to be used for the following experiment.

\subsection{Preparation of KGM/SL/E-PL Films}

After the addition of $0.20 \mathrm{~g}$ SL and $0.125 \mathrm{~g} \varepsilon-\mathrm{PL}$ powder into $100 \mathrm{~mL}$ deionized water respectively, the solution was mechanically stirred for $10 \mathrm{~min}$ to obtain $0.2 \% \mathrm{SL}$ and $0.125 \%$ $\varepsilon$-PL solution. Then $1.00 \mathrm{~g}$ KGM powder was added into the above solution and was thoroughly swelled with another $1 \mathrm{~h}$ agitation to obtain mixed KGM/SL/ $\varepsilon-\mathrm{PL}$ solution with $0.125 \% \varepsilon$-PL. When varied the amount of $\varepsilon$-PL powder was as $0.25,0.375$ and $0.50 \mathrm{~g}$ to obtain $0.25,0.375$ and $0.5 \%$ mixed KGM/SL/ $\varepsilon$-PL solutions, respectively. The solutions were centrifuged at $3000 \mathrm{rpm}$ for $6 \mathrm{~min}$ to degas. Each centrifuged solution $(30 \mathrm{~mL})$ was poured into a petri dish $(\Phi 90 \mathrm{~mm})$ which was wrapped by plastic with holes to allow water to evaporate. The mixed solution was dried in an oven $\left(50^{\circ} \mathrm{C}\right)$ to obtain intact $(0.125,0.25$, 0.375 and $0.5 \%) \mathrm{KGM} / \mathrm{SL} / \varepsilon-\mathrm{PL}$ composite films. The mechanical strength of all prepared films was evaluated as the method in 2.5. The composite film of KGM/SL/ $\varepsilon-P L$ with $0.2 \% \mathrm{SL}$ and $0.375 \% \varepsilon-\mathrm{PL}$ exhibited the strongest mechanical strength and elongation at break, so $0.2 \%$ SL and $0.375 \%$ - -PL were chosen as the optimal amount to be used for the following experiment.

\subsection{Mechanical Strength Evaluation of Films}

Those pieces free of defects (mainly no bubbles) were selected for symmetrical divergence by detecting 5 points (including one point in the center of the film and four symmetrical points around the film). The thickness of the films was measured with a spiral micrometer, and the average (accuracy $0.0001 \mathrm{~mm}$ ) was recorded. The thickness of the film provides the necessary index basis for the subsequent film strength test. A computer-controlled electronic tensile testing machine (WDW-5, Shenzhen, China) was used to determine its tensile strength (TS) and elongation at break (E). Before testing, the sample film strip was placed in a sealed box with a relative stable humidity $(50 \%)$ at room temperature $\left(25^{\circ} \mathrm{C}\right)$ for $48 \mathrm{~h}$ before testing. The longest distance between the upper and lower clamps was $50 \mathrm{~mm}$, and the speed rate was $0.5 \mathrm{~mm} / \mathrm{s}$. All experiments were carried out in triplicate and the results were shown as average value \pm SD. The tensile strength 
(TS) referred to the ratio of the maximum tensile tension (F) that the film could withstand before rupturing under the action of the axial tensile force and the product of the width (L) and thickness (D) of the film. The equation for calculating tensile strength was used as follows (1):

$$
\mathrm{TS}=\frac{\mathrm{F}}{\mathrm{L} \times \mathrm{D}}
$$

Here, TS corresponds to the tensile strength (MPa). F indicates the maximum tension (N) that the sample bears when it breaks. L and D are the width ( $\mathrm{mm}$ ) and the thickness of the sample (mm).

The calculation equation of elongation at break refers to (2):

$$
\mathrm{EB}=\frac{\mathrm{h}-\mathrm{H}}{\mathrm{H}} \times 100 \%
$$

Here, EB corresponds to the elongation at break (100\%). H and $\mathrm{h}$ are the length of the sample film before stretching $(\mathrm{mm})$ and the stretched length of the sample film $(\mathrm{mm})$.

Finally, Statistical Product and Service Solutions (SPSS) was used to statistically analyze the significance of the experimental results. Different letters indicate significant differences in data.

\subsection{Morphology Characterization by SEM}

A field emission scanning electron microscope (SEM 230, FEI, Hillsboro, OR, USA) was used to observe the microstructure of the film surface. Films were immersed in liquid nitrogen, and they were brittle and easily fractured at extremely low temperatures, and the microstructures of their cross-section were observed. Before the scanning electron microscope test, the films were fixed on the silicon wafer by conductive silica gel. Meanwhile, the surface of the film was gold-plated to make it conductive to obtain clear scanned images.

\subsection{Fourier Transforms Infrared (FTIR) Spectroscopy}

The films prepared above were dried and cut into pieces, and then mixed with potassium bromide, milled and pressed into pieces. The infrared spectrum absorption peak of the films was measured by Fourier infrared spectrometer (NEXUS 670, Waltham, MA, USA) [33-35].

\subsection{Thermogravimetric Analysis (TGA)}

The thermal properties of films were tested with a thermogravimetric analyzer (TGA WRT-12, Shanghai, China) in a nitrogen atmosphere with a flow rate of $25 \mathrm{~mL} / \mathrm{min}$. The test temperature increased from $25^{\circ} \mathrm{C}$ to $800{ }^{\circ} \mathrm{C}$ at a heating rate of $10^{\circ} \mathrm{C} / \mathrm{min}$, and the thermal curves were recorded [36].

\subsection{Antibacterial Properties}

Escherichia coli (ATCC 11775) and Staphylococcus aureus (ATCC 27735) are representative Gram-negative bacteria and Gram-positive bacteria. These two bacteria were used to evaluate the antibacterial properties of the films. Here, we judge whether the bacterial growth is in the logarithmic phase, which is determined by the bacterial growth curve. Use a 96-well culture plate to grow bacteria and count them. The growth curve is drawn with the culture time as the abscissa and the bacterial count as the ordinate. When the bacteria grow logarithmically, it is the logarithmic phase. Bacteria in the logarithmic phase $\left(200 \mu \mathrm{L}\right.$ of $\left.1 \times 10^{3} \mathrm{CFU} / \mathrm{mL}\right)$ with the best vitality were chosen and cultured in the solid agar medium at $37^{\circ} \mathrm{C}$ for $24 \mathrm{~h}$. After the injection of a bacterial solution into the medium, the bacterial solution was homogeneously spread and then dried for use later. The films were placed on a clean bench for UV sterilization for $30 \mathrm{~min}$ and then were cut into small discs $(\Phi 15 \mathrm{~mm}$ ) with a puncher. The discs were carefully pasted on the surface of the plate culture medium. Three pieces of each medium were attached to reduce the salt error. The 
plate was placed upside down in an incubator $\left(37^{\circ} \mathrm{C}, 24 \mathrm{~h}\right)$. Then the diameters of the inhibition zone were measured and photographed.

\section{Results}

\subsection{Characterization of the Film}

\subsubsection{Process Optimization of Composite Films by Mechanical Properties}

The crosslinking of the polymers of the film is shown in Figure 1, which explains the mechanical properties of the film to a certain extent. According to the research experience of our group, $1 \%$ KGM optimized gel concentration was used in composite films preparation. On basis of $1 \% \mathrm{KGM}$, films with varied SL concentrations of $0,0.1,0.2,0.3,0.5,1.0 \%$ were prepared. The thickness of the film affects the tensile strength (Equation (1)), so the thickness of the film was measured as showed in Table 1. The tensile strength and elongation at break (shown in Table 1) of the films were obtained by the tensile strength test. SPSS statistical analysis results show that different letter superscripts indicate that the test results have significant differences and have reference significance. The stress-strain curves (shown in Figure 2A-C) have summarized the tensile strength variance of films with different combinations of KGM, SL and $\varepsilon$-PL. As showed in Figure 2A, films were prepared with stable $\operatorname{KGM}(1 \%, w / v)$ and varied SL amounts $(0,0.1,0.2,0.3,0.5,1.0 \%, w / v)$. From which, it could be observed that as the concentration of SL increased, the initial tensile strength increased and then decreased. We obtained the optimal concentration of SL. The maximum tensile strength is $108.55 \pm 8.50 \mathrm{MPa}$ (SL 0.2\%), and the minimum is $38.56 \pm 6.18 \mathrm{MPa}$ (SL 1.0\%) which might be that SL itself has a certain strength due to its rigid network. However, SL lacks flexibility, so that the concentration is too high and the brittleness becomes remarkable, which leads to a decrease in the elongation at the break of the film. In addition, the phenolic hydroxyl and sulfonic acid groups in SL enhance the hydrogen bonding force within the KGM molecular chains, thereby improving the mechanical strength of the original KGM film. At the same time, the electrostatic interaction between cationic polymer $\varepsilon$-PL and anionic polymer SL also further enhances the force between the components of the composite film. The results also confirmed that KGM/SL films with an SL concentration of $0.2 \%$ had better mechanical properties than other films with different SL concentrations.

Table 1. Thickness and mechanical performance of films with different components.

\begin{tabular}{|c|c|c|c|}
\hline Sample & Thickness $(\mu \mathrm{m})$ & Tensile Strength (MPa) & Elongation at Break (\%) \\
\hline KGM & $26.80 \pm 1.30^{\mathrm{i}}$ & $49.91 \pm 5.88^{\mathrm{d}}$ & $24.89 \pm 4.51^{\mathrm{e}}$ \\
\hline SL0.1\% & $33.20 \pm 2.00 \mathrm{gh}$ & $72.29 \pm 5.10^{c}$ & $45.23 \pm 4.52^{\mathrm{d}}$ \\
\hline SL0.2\% & $38.20 \pm 2.80$ ef & $108.55 \pm 8.50^{\mathrm{a}}$ & $40.08 \pm 0.56^{\mathrm{d}}$ \\
\hline SL0.3\% & $41.40 \pm 5.90 \mathrm{de}$ & $105.19 \pm 4.52^{\mathrm{a}}$ & $62.81 \pm 3.50^{\mathrm{c}}$ \\
\hline SL0.5\% & $58.20 \pm 1.60^{b}$ & $63.36 \pm 3.50^{c}$ & $23.80 \pm 3.04^{\mathrm{e}}$ \\
\hline SL1.0\% & $70.00 \pm 3.10^{\mathrm{a}}$ & $38.56 \pm 6.18^{\mathrm{de}}$ & $28.45 \pm 5.07^{\mathrm{e}}$ \\
\hline PL0.125\% & $28.80 \pm 3.00 \mathrm{hi}$ & $33.40 \pm 9.56^{\mathrm{e}}$ & $93.54 \pm 3.02^{\mathrm{a}}$ \\
\hline PL0.250\% & $36.80 \pm 3.30$ efg & $40.13 \pm 4.03 \mathrm{de}$ & $71.87 \pm 4.05^{b}$ \\
\hline PL0.375\% & $35.80 \pm 3.60 \mathrm{fg}$ & $42.38 \pm 5.50$ de & $93.57 \pm 3.02^{\mathrm{a}}$ \\
\hline PL0.500\% & $37.00 \pm 3.40$ efg & $33.55 \pm 5.50^{\mathrm{e}}$ & $95.01 \pm 5.00^{\mathrm{a}}$ \\
\hline KGM1 & $43.80 \pm 4.40^{\mathrm{cd}}$ & $70.21 \pm 7.54^{\mathrm{c}}$ & $70.03 \pm 6.56 b^{c}$ \\
\hline KGM2 & $43.80 \pm 4.40^{\mathrm{cd}}$ & $89.41 \pm 7.14^{b}$ & $91.67 \pm 6.05^{\mathrm{a}}$ \\
\hline KGM3 & $45.40 \pm 5.10^{\mathrm{cd}}$ & $105.97 \pm 4.58^{\mathrm{a}}$ & $95.71 \pm 5.02^{\mathrm{a}}$ \\
\hline KGM4 & $46.60 \pm 2.40^{\mathrm{c}}$ & $97.12 \pm 7.00^{a b}$ & $91.47 \pm 1.04^{\mathrm{a}}$ \\
\hline
\end{tabular}

Different superscript letters indicate a significant difference between the means $(p<0.05)$.

It can be informed from Figure $2 \mathrm{~B}$ that $\mathrm{KGM} / \varepsilon$-PL films have no obvious advantage in tensile strength, but the elongation at the break of the film is greatly improved. As shown in Figure 2C, there are stress curves of films with increasing $\varepsilon$-PL concentration $(0.125,0.25$, $0.375,0.5 \%)$ but stable concentration of KGM $(1 \%)$ and SL $(0.2 \%)$. Too high a concentration of $\mathcal{\varepsilon}$-PL will greatly facilitate interaction with KGM and SL to form an aggregate of small 
particles, which will affect the uniformity of the film; thus, the test is not performed. The mechanical strength of the KGM/SL/ $\mathcal{E}$-PL composite film is much stronger than that of the pure KGM film (as control) with the minimum stress and strain. According to the control experiment, it reveals that SL greatly enhances the tensile strength of the film, while $\varepsilon$-PL greatly enhances the elongation at the break of the film. The results show that the optimized ratio of the matrix is $1 \% \mathrm{KGM}, 0.2 \% \mathrm{SL}, 0.375 \% \varepsilon-\mathrm{PL}$.
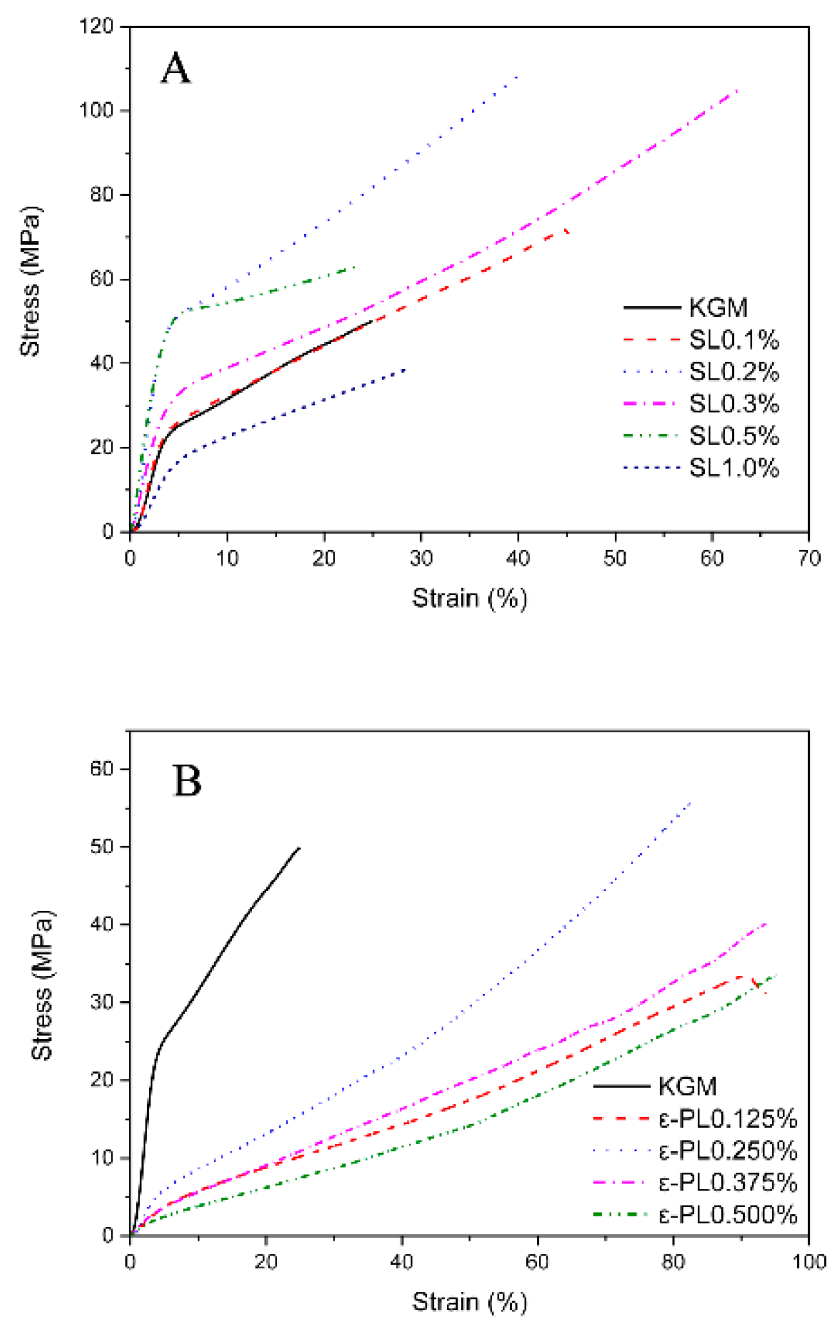

Figure 2. The stress-strain curves of the KGM/SL (A), KGM/ $\varepsilon$-PL (B), KGM/SL/ $\varepsilon$-PL (C) films with different components.

\subsubsection{Morphology Characterization}

The microstructure of the films was observed by SEM (Figure 3). The surface (left) and cross-section (right) of the films were viewed with a magnification of $1.00 \mathrm{~K}$ and $5.00 \mathrm{~K}$ as showed in Figure 3 A, B, C, and D corresponding to KGM, KGM/SL, KGM/ $\varepsilon$-PL and $\mathrm{KGM} / \mathrm{SL} / \varepsilon$-PL films, respectively. It could be observed from Figure $3 \mathrm{~A}$ that the bubbles like particles of KGM were significantly more than those of KGM/SL, KGM/ $\varepsilon-\mathrm{PL}$ and $\mathrm{KGM} / \mathrm{SL} / \varepsilon$-PL. Additionally, under the same stirring conditions, the KGM film appeared undissolved particles, which also confirmed that SL can enhance the dispersibility of the system. Under the same processing conditions, KGM had a strong affinity with water molecules due to the presence of hydrophilic acetyl groups and a large number of hydroxyl groups. The large molecular weight and a long chain of KGM making it difficult to remove bubbles. The addition of SL and $\varepsilon$-PL enable the solution to possess good fluidity and could be easier to remove bubbles. By observing the cross-section of the film, we found that the gap in the Figure $3 \mathrm{~B}$ image is more obvious, which is related to the brittleness of 
SL found in our tensile test. The cross-section of the composite membrane seems denser, which is the same as the result of the tensile test.
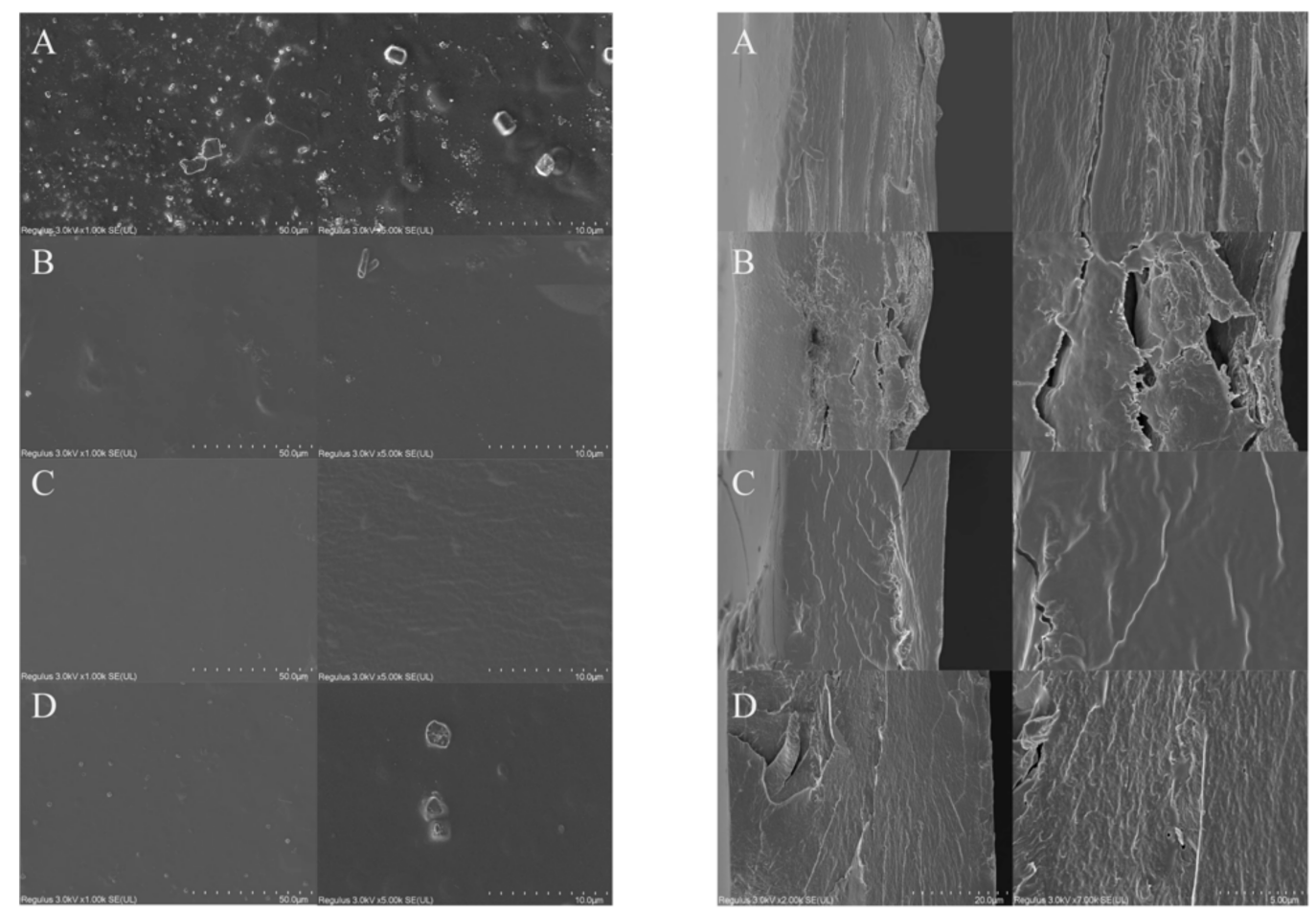

Figure 3. SEM images of the film surface (left) and cross section (right): (A) KGM (KGM 1\%) film, (B) KGM/SL (KGM 1\%, SL 0.2\%) film, (C) KGM/ $\varepsilon$-PL (KGM 1\%, $\varepsilon$-PL 0.375\%) film, (D) KGM/SL/ $\varepsilon$-PL (KGM 1\%, SL $0.2 \%$, ع-PL $0.375 \%$ ) film.

\subsubsection{Fourier Transforms Infrared (FTIR) Spectroscopy}

The chemical structure of KGM and KGM composite films was analyzed by FTIR (Figure 4). The spectrum of neat KGM shows some absorption peaks potentially sensitive to intermolecular interactions. These are bands at $3280 \mathrm{~cm}^{-1}$, assigned to the stretching of -OH groups. SL in KGM matrix leads to intensity variation of mentioned bands, which could be ascribed to the interaction between the -OH group on the SL surface and the hydroxyl groups of the KGM matrix. Slight modifications in the intensity of some peaks relating to SL are also visible at $1560 \mathrm{~cm}^{-1}$ (C-C stretching of the aromatic skeleton). In the case of KGM/ $\varepsilon$-PL blending film, the two main characteristic peaks related to $\mathrm{C}-\mathrm{H}$ were shifted towards higher wavenumbers $\left(\right.$ at $1630 \mathrm{~cm}^{-1}$ ) due to the interaction between -OH and $-\mathrm{NH}_{2}$ with bending vibration in $\mathrm{KGM} / \varepsilon-\mathrm{PL}$ [37]. The absorption peak of $\mathrm{C}=\mathrm{O}$ of the $\varepsilon$-PL structure was located at the wavelength of $1663 \mathrm{~cm}^{-1}$ conforming to the reference [38]. The shift of peak at around $2936 \mathrm{~cm}^{-1}$ to a lower frequency range may be due to hydrogen bonds among $-\mathrm{OH},-\mathrm{SO}_{3} \mathrm{H}$ and $-\mathrm{NH}_{2}$ in the films [39]. According to the analysis and comparison of the database, $2936 \mathrm{~cm}^{-1}$ and $2874 \mathrm{~cm}^{-1}$ in the KGM infrared spectrum represented the stretching vibration absorption peaks of $-\mathrm{CH}_{2}-$ [40]. The absorption peak at $1132 \mathrm{~cm}^{-1}$ without obvious change could be assigned as the absorption peak of in-plane bending vibration of the alcoholic hydroxyl group. 

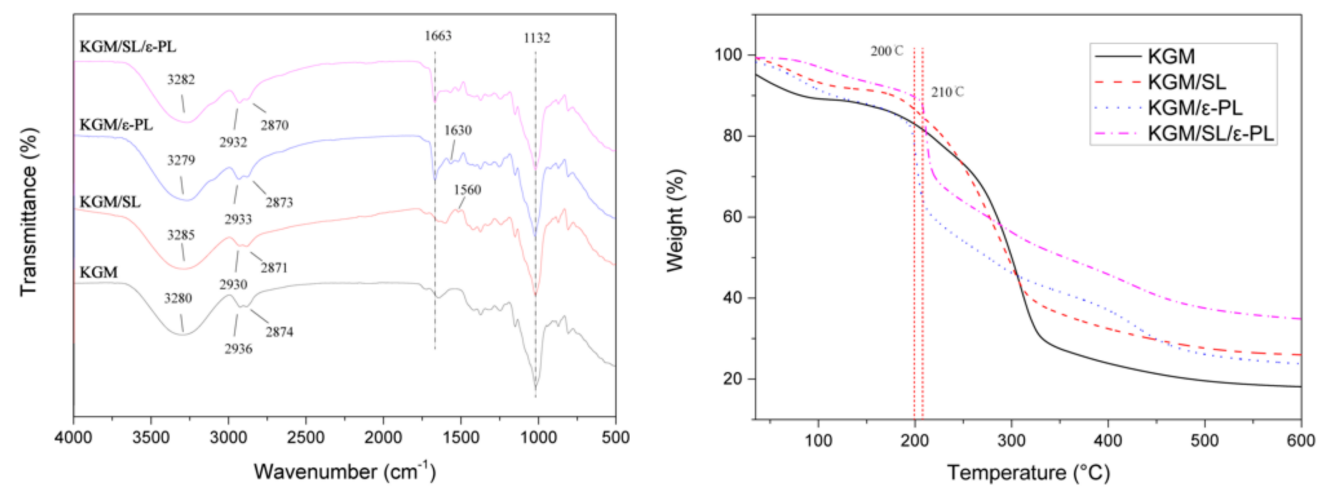

Figure 4. FITR and TGA curves of KGM (KGM 1\%), KGM/SL (KGM 1\%, SL 0.2\%), KGM/ $\varepsilon$-PL (KGM 1\%, $\varepsilon$-PL $0.375 \%$ ) and KGM/SL/ $\mathcal{E}$-PL (KGM 1\%, SL 0.2\%, $\varepsilon$-PL 0.375\%) films.

\subsubsection{Thermogravimetric Analysis (TGA)}

The thermal behavior of KGM and KGM composite films was assessed by TGA (Figure 4) at a temperature ranging from 30 to $600{ }^{\circ} \mathrm{C}$. The typical degradation of KGM is divided into three weight loss steps. The first step (in the $50-200{ }^{\circ} \mathrm{C}$ region) is related to the volatilization and evaporation of water. Water loss of KGM in the first step is due to its hydrophily [31]. In the second step, all films showed a large amount of mass loss at $200-325{ }^{\circ} \mathrm{C}$ deriving from thermal degradation of KGM, SL and $\varepsilon$-PL. The initial pyrolysis temperature of $\mathrm{KGM}, \mathrm{KGM} / \mathrm{SL}$, and $\mathrm{KGM} / \varepsilon$-PL was less than $200^{\circ} \mathrm{C}$, while the initial pyrolysis temperature of $\mathrm{KGM} / \mathrm{SL} / \varepsilon-\mathrm{PL}$ was approximately at $210^{\circ} \mathrm{C}$. The weight loss of the KGM film was greatly slowed down at around $330^{\circ} \mathrm{C}$ [32]. The increase in the pyrolysis temperature of the KGM/SL/ $\varepsilon$-PL composite film proves that the thermal stability of the film was improved, which may be due to the increase in the hydrogen bond force between $-\mathrm{OH}$ of $\mathrm{SL},-\mathrm{NH}_{2}$ of $\varepsilon-\mathrm{PL}$ and -OH of KGM [35]. The interactions including van der Waals forces between components of composite film were enhanced and finally exhibited by the enhancement of the thermal stability, mechanical strength [41].

\subsubsection{Antibacterial Properties}

The antibacterial activities of the film against Escherichia coli and Staphylococcus aureus were evaluated by $24 \mathrm{~h}$ co-culturation (Figure 5). Figure 5A-D refer to the inhibition of E. coli by KGM, KGM/SL, KGM/ $\varepsilon$-PL and $\mathrm{KGM} / \mathrm{SL} / \varepsilon$-PL films respectively. It can be found that both $\mathrm{KGM} / \varepsilon-\mathrm{PL}$ and $\mathrm{KGM} / \mathrm{SL} / \varepsilon$-PL films show obvious inhibition zones with inhibitory diameters of $26.87 \pm 0.24 \mathrm{~mm}$ and $22.50 \pm 0.31 \mathrm{~mm}$ (Figure 5C,D), while the KGM, KGM/SL films have no inhibitory diameter (Figure 5A,B) which meant that the added $\varepsilon$-PL has obvious antibacterial properties [42]. The final antibacterial activity of the composite film is weaker than that of $\mathrm{KGM} / \varepsilon-\mathrm{PL}$ film due to the decreased mass proportion of $\varepsilon$-PL. As shown in the inhibition effects of KGM and KGM/SL/ $\varepsilon$-PL films against Staphylococcus aureus are shown in Figure 5E,F, which revealed that the KGM film showed no antibacterial effect on Staphylococcus aureus, while an obvious inhibition zone is formed around the KGM/SL/ $\varepsilon$-PL film with a diameter of $19.69 \pm 0.36 \mathrm{~mm}$. In summary, it is found that the KGM/SL/ $\varepsilon$-PL composite film shows an advanced inhibitory effect on bacterial compared with other films. That is to say, the addition of $\varepsilon$-PL significantly improves the antibacterial effect of the composite film. 


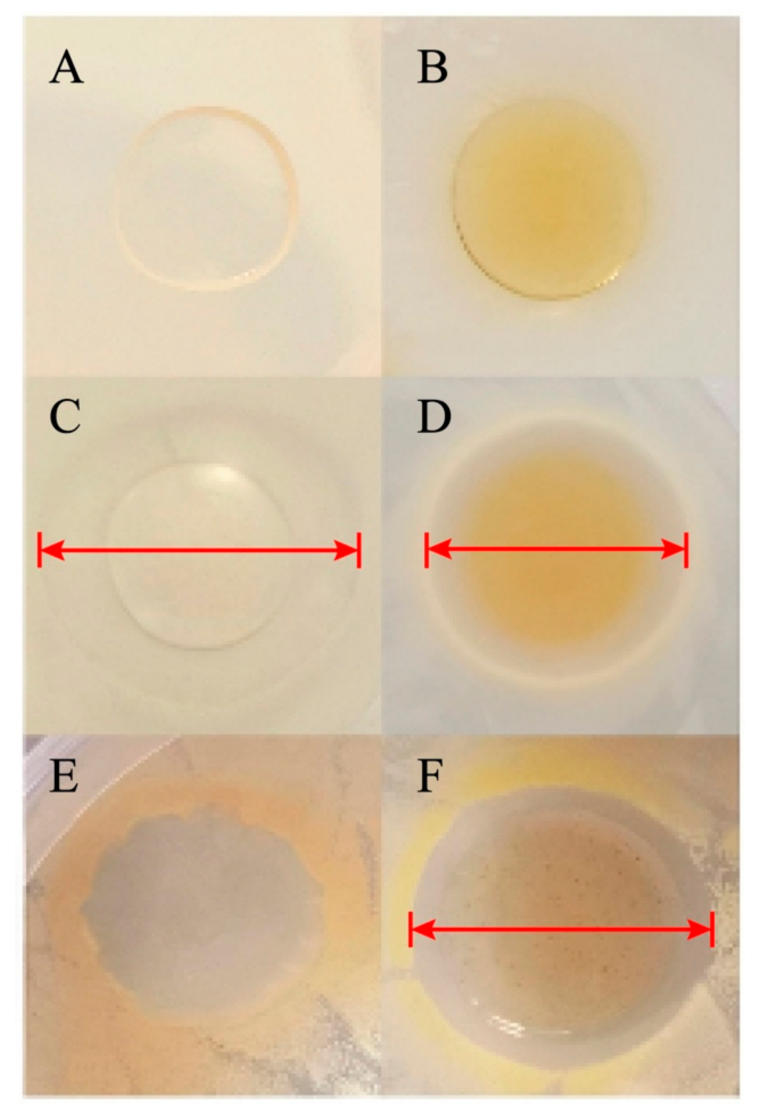

Figure 5. Antibacterial activity of films against Escherichia coli and Staphylococcus aureus in coculturation mode: (A) KGM (KGM 1\%) film (E. coli), (B) KGM/SL (KGM 1\%, SL 0.2\%) film (E. coli),

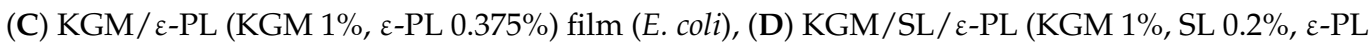
$0.375 \%$ ) film (E. coli), (E) KGM (KGM 1\%) film (Staphylococcus aureus), (F) KGM/SL/ $\varepsilon$-PL (KGM 1\%, SL $0.2 \%$, $\varepsilon$-PL $0.375 \%$ ) film (Staphylococcus aureus).

\section{Conclusions}

In this study, the tensile properties, thermal stability, and antibacterial properties of the KGM/SL/ $\varepsilon$-PL composite film had been significantly improved by introducing $\mathrm{SL}$ and $\varepsilon$-PL. The tensile strength of the composite film is significantly increased to $105.97 \pm 4.58 \mathrm{MPa}$ (compared to $49.91 \pm 5.88 \mathrm{MPa}$ of the KGM film, $p<0.05$ ). Meanwhile, different concentration gradients were used to screen the optimal component of $\mathrm{KGM} / \mathrm{SL}$ and KGM/ $\varepsilon$-PL films. By comparing with KGM, it is found that an appropriate $\mathrm{SL}$ concentration can increase the tensile strength and elongation at the break of the film. Moreover, the addition of $\varepsilon$-PL significantly increased the elongation at the break of the film. The screening results show that the optimized ratio of KGM/SL/ $\varepsilon-\mathrm{PL}$ film is: $\mathrm{KGM} 1 \%$, SL $0.2 \%$ and $\varepsilon$-PL $0.375 \%$. Finally, the thermal stability of composite film is improved by introducing SL and $\varepsilon$-PL and has the strongest thermal stability under high-temperature pyrolysis conditions. The addition of $\varepsilon$-PL enabled the film to possess the expected antibacterial properties. It has proved that the composite film can be a good candidate for food packaging. Compared with the one-component pure KGM packaging film, the composite film has significantly enhanced mechanical properties, which helps to enhance the protection and applicability of food packaging. Enhanced thermal stability and antibacterial properties also provide the possibility to improve the durability of composite films in food packaging. At the same time, the use of natural biological materials makes the film more biodegradable, which is conducive to environmental protection and sustainable development and shows potential in the field of food green packaging. In addition, the preparation of composite films can be further improved. For example, enhance the fluidity of KGM to reduce bubbles, thereby improving the uniformity of film formation; further 
research to improve the air permeability, water solubility and oxidation resistance of the composite film; in-depth study of the mechanism of film polymer molecules to produce stronger mechanical performance biodegradable food packaging film.

Author Contributions: Conceptualization, J.P. and X.X.; resources, J.P.; data curation, X.X.; writingoriginal draft preparation, X.X.; writing-review and editing, X.X.; supervision, J.P.; project administration, J.P.; funding acquisition, J.P. All authors have read and agreed to the published version of the manuscript.

Funding: This research was funded by the National Natural Science Foundation of China, grant number 31772045 and the APC was funded by 31772045.

Institutional Review Board Statement: Not applicable.

Informed Consent Statement: Not applicable.

Acknowledgments: This work was supported by the National Natural Science Foundation of China.

Conflicts of Interest: We confirm that all authors have read this manuscript and none of the material related to this manuscript has been published or is under consideration for publication elsewhere, including the internet. We confirm that we have provided a current, correct email address which is accessible by the Corresponding Author.

\section{References}

1. Nishinari, K. Konjac glucomannan. Dev. Food Sci. 2000, 41, 309-330. [CrossRef]

2. Rhim, J.W.; Wang, L.F. Mechanical and water barrier properties of agar/k-carrageenan/konjac glucomannan ternary blend biohydrogel films. Carbohydr. Polym. 2013, 96, 71-81. [CrossRef]

3. Li, B. Quick dissolvable, edible and heatsealable blend films based on konjac glucomannan-Gelatin. Food Res. Int. 2005, 39, 544-549. [CrossRef]

4. Kobayashi, S. Preparation and rheological characterization of carboxymethyl konjac glucomannan. Food Hydrocoll. 2002, 16, 289-294. [CrossRef]

5. Cheng, L.H.; Karim, A.A.; Seow, C.C. Characterisation of composite films made of konjac glucomannan (KGM), carboxymethyl cellulose (CMC) and lipid. Food Chem. 2007, 107, 411-418. [CrossRef]

6. Qiao, D.L.; Lei, W.Y. Microstructure and mechanical/hydrophilic features of agar-based films incorporated with konjac glucomannan. Polymers 2019, 11, 1952. [CrossRef] [PubMed]

7. Li, B.; Xie, B. Synthesis and characterization of konjac glucomannan/poly (vinyl alcohol) interpenetrating polymer networks. J. Appl. Polym. Sci. 2010, 93, 2775-2780. [CrossRef]

8. Li, B. Effect of gamma irradiation on the condensed state structure and mechanical properties of konjac glucomannan/chitosan blend films. Carbohydr. Polym. 2010, 83, 44-51. [CrossRef]

9. Wang, L. Interactions between carboxymethyl konjac glucomannan and soy protein isolate in blended films. Carbohydr. Polym. 2013, 101, 136-145. [CrossRef] [PubMed]

10. Maryam, H.; Haruna, Y.; Wang, J. Konjac glucomannan-based composite films fabricated in the presence of carnauba wax emulsion: Hydrophobicity, mechanical and microstructural properties evaluation. J. Food Sci. 2019, 56, 5138-5145. [CrossRef]

11. Ma, Q.; Wang, L.; Zhai, H.; Ren, H. Lignin dissolution model in formic acid-acetic acid-water systems based on lignin chemical structure-sciencedirect. Int. J. Biol. Macromol. 2021, 182, 51-58. [CrossRef]

12. Hen, F.C.; Dixon, R.A. Lignin modification improves fermentable sugar yields for biofuel production. Nat. Biotechnol. 2007, 25, 759. [CrossRef]

13. Shen, Z. High-Value Utilization of Lignin to Synthesize Ag Nanoparticles with Detection Capacity for Hg2 ${ }^{+}$. ACS Appl. Mater. Interfaces 2014, 6, 16147-16155. [CrossRef]

14. Pj, A.; Mncb, C.; Tj, A. The role of lignin and lignin-based materials in sustainable construction-A comprehensive review. Int. J. Biol. Macromol. 2021, 187, 624-650. [CrossRef]

15. Yang, Z. High-Value Utilization of Lignin to Prepare Functional Carbons toward Advanced Lithium-Ion Capacitors. ACS Sustain. Chem. Eng. 2020, 8, 11522-11531. [CrossRef]

16. Chen, Y. High-value utilization of hydroxymethylated lignin in polyurethane adhesives. Int. J. Biol. Macromol. 2020, 152, 775-785. [CrossRef] [PubMed]

17. Kleinhans, H.; Salmén, L. Development of lignin carbon fibers: Evaluation of the carbonization process. J. Appl. Polym. Sci. 2016, 133, 43965. [CrossRef]

18. Medina-Carrillo, R.E. Secondary Metabolites and Lignin in 'Hass' Avocado Fruit Skin during Fruit Development in Three Producing Regions. Hortscience 2017, 52, 852-858. [CrossRef]

19. Wang, Z.J.; Lan, T.Q.; Zhu, J.Y. Lignosulfonate and elevated pH can enhance enzymatic saccharification of lignocelluloses. Biotechnol. Biofuels 2013, 6, 9. [CrossRef] 
20. Prasetyo, E.N. Polymerization of lignosulfonates by the laccase-HBT (1-hydroxybenzotriazole) system improves dispersibility. Bioresour. Technol. 2010, 101, 5054-5062. [CrossRef]

21. Zhang, J.; Liu, J.; Liu, R. Effects of pyrolysis temperature and heating time on biochar obtained from the pyrolysis of straw and lignosulfonate. Bioresour. Technol. 2015, 176, 288-291. [CrossRef] [PubMed]

22. He, B. Rheological properties of lignosulfonate intercalated layered double hydroxides modified bitumen before and after ultraviolet aging. Constr. Build. Mater. 2018, 180, 342-350. [CrossRef]

23. He, B. Preparation and characterization of lignosulfonate grafted layered double hydroxides and their applications as antiultraviolet additives for bitumen. Constr. Build. Mater. 2019, 195, 432-440. [CrossRef]

24. Islas-Valdez, S. Assessing metal-lignosulfonates as fertilizers using gel filtration chromatography and high-performance size exclusion chromatography. Int. J. Biol. Macromol. 2020, 142, 163-171. [CrossRef]

25. Zhang. Lignosulfonate as reinforcement in polyvinyl alcohol film: Mechanical properties and interaction analysis. Int. J. Biol. Macromol. Struct. Funct. Interact. 2016, 83, 209-215. [CrossRef] [PubMed]

26. Liang, C.; Yuan, F.; Liu, F.; Wang, Y.; Gao, Y. Structure and antimicrobial mechanism of $\varepsilon$-polylysine-chitosan conjugates through maillard reaction. Int. J. Biol. Macromol. 2014, 70, 427-434. [CrossRef]

27. Lan, W. $\varepsilon$-Polylysine Inhibits Shewanella putrefaciens with Membrane Disruption and Cell Damage. Molecules $2019,24,3727$. [CrossRef]

28. Shao, Z.; Yang, Y.; Fang, S.; Li, Y.; Chen, J.; Meng, Y. Mechanism of the antimicrobial activity of whey protein- $\varepsilon-$ polylysine complexes against Escherichia coli and its application in sauced duck products. Int. J. Food Microbiol. 2020, 328, 108663. [CrossRef]

29. Li, Y.Q. Effects of $\varepsilon$-Polylysine on Physicochemical Characteristics of Chilled Pork. Food Bioprocess. Technol. 2014, 7, 2507-2515. [CrossRef]

30. Wu, C.; Li, Y.; Sun, J. Novel konjac glucomannan films with oxidized chitin nanocrystals immobilized red cabbage anthocyanins for intelligent food packaging. Food Hydrocoll. 2020, 98, 105245.1-105245.11. [CrossRef]

31. Wang, L.; Mu, R.J.; Li, Y. Characterization and antibacterial activity evaluation of curcumin loaded konjac glucomannan and zein nanofibril films. LWT Food Sci. Technol. 2019, 113, 108293. [CrossRef]

32. Wei, X.; Pang, J.; Zhang, C. Structure and properties of moisture-resistant konjac glucomannan films coated with shellac/stearic acid coating. Carbohydr. Polym. 2015, 118, 119-125. [CrossRef]

33. Wu, C.; Yang. Enhanced functional properties of biopolymer film incorporated with curcurmin-loaded mesoporous silica nanoparticles for food packaging. Food Chem. 2019, 288, 139-145. [CrossRef] [PubMed]

34. Cortés, V.; Barat, J.M.; Talens, P. A comparison between NIR and ATR-FTIR spectroscopy for varietal differentiation of Spanish intact almonds. Food Control 2018, 94, 241-248. [CrossRef]

35. Xiao, C.; Gao, S.; Zhang, L. Blend films from konjac glucomannan and sodium alginate solutions and their preservative effect. J. Appl. Polym. Sci. 2015, 77, 617-626. [CrossRef]

36. Lin, W.; Ni, Y.; Pang, J. Size effect-inspired fabrication of konjac glucomannan/polycaprolactone fiber films for antibacterial food packaging. Int. J. Biol. Macromol. 2020, 149, 853-860. [CrossRef] [PubMed]

37. Yang, W.; Owczarek, J.S.; Fortunati, E. Antioxidant and antibacterial lignin nanoparticles in polyvinyl alcohol/chitosan films for active packaging. Ind. Crops Prod. 2016, 94, 800-811. [CrossRef]

38. Cheng, H.; Yang, J.; Frost, R.L. Thermal analysis and Infrared emission spectroscopic study of kaolinite-potassium acetate intercalate complex. J. Therm. Anal. Calorim. 2011, 511, 124-128. [CrossRef]

39. Ahmad, M.; Sirajuddin, M.; Akther, Z. Stannic chloride-para toluene sulfonic acid as a novel catalyst-co-catalyst system for the designing of hydroxyl terminated polyepichlorohydrin polymer: Synthesis and characterization. Spectrochim. Acta Part A Mol. Biomol. Spectrosc. 2015, 151, 164-173. [CrossRef]

40. Kai, W.; Wu, K.; Man, X. Structural characterization and properties of konjac glucomannan and zein blend films. Int. J. Biol. Macromol. 2017, 105, 1096-1104. [CrossRef]

41. Dini, A.; Zandi-Baghche-Maryam, A.; Shariati, M. Effects of van der Waals forces on hygro-thermal vibration and stability of fluid-conveying curved double-walled carbon nanotubes subjected to external magnetic field. Phys. E Low-Dimens. Syst. Nanostructures 2018, 106, 156-169. [CrossRef]

42. Liu, H.; Pei, H.; Han, Z. The antimicrobial effects and synergistic antibacterial mechanism of the combination of $\varepsilon$-Polylysine and nisin against Bacillus subtilis. Food Control 2015, 47, 444-450. [CrossRef] 